\title{
Sex of offspring influences metabolism during early transition period in dairy cows
}

\author{
D. Alberghina ${ }^{1}$, G. Piccione ${ }^{1}$, C. Giannetto ${ }^{1}$, M. Morgante ${ }^{2}$, and M. Gianesella ${ }^{2}$ \\ ${ }^{1}$ Department of Veterinary Sciences, University of Messina, Polo Universitario dell'Annunziata, Messina, Italy \\ ${ }^{2}$ Department of Animal Medicine, Productions and Health (MAPS), University of Padua, Padua, Italy \\ Correspondence to: D. Alberghina (dalberghina@unime.it)
}

Received: 24 October 2014 - Accepted: 23 January 2015 - Published: 4 March 2015

\begin{abstract}
A study using 20 Holstein Friesian cows was conducted to investigate the influence of calf gender on metabolism during the transition period in dairy cattle. Blood samples were collected at three time points: 2-4 days prepartum (time 1), and 1 week and 2 weeks postpartum (time 2 and time 3 respectively). Serum samples obtained were analysed for total proteins, albumin, urea, glucose, non-esterified fatty acids (NEFA) and $\beta$-hydroxybutyrate (BHB). Depending on the sex of the offspring, cows were divided into two groups: Group 1 consisted of cows with heifer offspring $(n=12)$ and Group 2 consisted of cows with bull offspring $(n=8)$. A two-way repeated measures ANOVA and $t$ tests for unpaired data were used to analyse the pattern of studied parameters and differences between the two groups. The results indicate differences in metabolic parameters between the two groups. These results highlight the importance of considering fetal sex as a factor that influences maternal metabolism during the early transition period in dairy cows.
\end{abstract}

\section{Introduction}

The ability of an individual to adapt to the natural change of energy balance during early lactation is an important aspect of the transition period for dairy cows. During this period, the cow undergoes physiological, metabolic and nutritional changes. As this period presents a huge metabolic challenge to high-yielding dairy cows, any changes in haematochemical profiles are important (Piccione et al., 2012; Tóthová et al., 2014). Cows that are unable to adapt adequately to these changes often develop hyperketonemia, which can also cause other health complications.

In dairy cows, key metabolic parameters used as indicators of negative energy balance (NEB) and subclinical ketosis are non-esterified fatty acids (NEFA) and $\beta$-hydroxybutyrate (BHB) (Oetzel, 2004). Recently, blood NEFA concentrations have been found to be a more accurate measure of NEB than ketone bodies (McArt et al., 2013b). Among the predictors of early lactation hyperketonemia, calf sex may be important in identifying cows that are at risk for developing hyperketonemia. For instance, cows with bull calves were reported to be more likely to develop hyperketonemia than those with female calves (McArt et al., 2013a).
Fetal sex can also affect different aspects of dairy cows, such as "days open" as well as milk production. In one study, cows with bull calves had fewer days open than cows with heifer calves (Cordova-Izquierdo et al., 2008). The number of days between calving and conception affects profitability in terms of breeding cost, increased risk of culling and replacement costs; hence, long days open reduce profitability (De Vries, 2004). Other studies have shown that a positive relationship between age at first calving and milk production (Müller et al., 2005), and a significant biological effect of sex-biased milk production in favour of daughters (Hinde et al., 2014) exists in Holstein dairy cows.

While many studies have focused on how mammalian females could influence the sex of the offspring both before and after conception (Hardy, 1997; Grant et al., 2008; Grant and Chamley, 2010), there is little understanding of how offspring sex can affect metabolism in dairy cows during the transition period. Fetal hormones may provide a means for understanding the influence of offspring sex on maternal metabolism during the early transition period, especially since they can readily diffuse into maternal circulation. Ruminants may be especially valuable for understanding mam- 
mary gland development during pregnancy as a function of fetal sex because of their cotyledonary placenta. As a by-product of the greater placental surface area, fetal hormones can readily diffuse into maternal circulation (Klisch and Mess, 2007).

Currently, it is known that the amount of hormone insulinlike peptide 3 (INSL3), a major secretory product of the Leydig cells from both fetal and adult testes, declines during mid-pregnancy and is undetectable in cows carrying a female fetus. In contrast, circulating maternal INSL3 increases in cows carrying a male fetus. This increase in INSL3 levels may be a result of the transplacental transfer of fetal INSL3 into maternal circulation. While this gender-specific fetal hormone may influence both placental and maternal physiology (Anand-Ivell et al., 2011), the extent to which fetal-origin INSL3 influences mammary gland development is unknown.

In general, cows undergo significant metabolic changes during the early transition period; however, these changes are greater in Holstein Friesian cows than in other breeds (Adamski et al., 2011; Kupczyński et al., 2011). A greater understanding of how the sex of the offspring influences these changes could provide insight to clinicians and producers on ways of reducing risk of hyperketonemia and other diseases in dairy cows. Therefore, the aim of this study was to evaluate differences in metabolic parameters during the early transition period in dairy cows calving bulls or heifers.

\section{Material and methods}

Twenty multiparous Holstein Friesian cows belonging to an intensive dairy herd located in northern Italy $\left(45^{\circ} 24^{\prime} \mathrm{N}\right.$, $11^{\circ} 52^{\prime} \mathrm{E} ; 12 \mathrm{~m}$ above sea level) were used for the study. Cows (second parity no. 3 ; third parity no. 5 , fourth/fifth parity no. 12) were subjected to a dry period of 60 days and a steaming-up period of 15 days prior to calving. All animals were clinically healthy and kept free from internal and external parasites before and during the study. The health status of each cow (behaviour, rectal temperature, heart rate, respiratory profile, cough, nasal and ocular discharge, and haematological profile) was recorded. Table 1 lists the chemical composition of diets used during steaming-up and subsequent early lactation. Water was available ad libitum. All housing and care conditions conformed to the standards recommended by the Guide for the Care and Use of Laboratory Animals, Directive 2010/63/EU and Directive 1998/58/EU.

Blood samples were collected by jugular venipuncture into $10 \mathrm{~mL}$ Vacutainer tubes (Terumo Corporation, Tokyo, Japan) at three different time points between 08:00 and 09:00 (central european standard time $=$ GMT +1$)$ : (1) 2-6 days prepartum (T1), (2) 7 days postpartum (DPP) (T2), and (3) 14 DPP (T3). Whole blood was centrifuged at $1350 \times g$ for $10 \mathrm{~min}$. Serum was stored within $1 \mathrm{~h}$ at $-20^{\circ} \mathrm{C}$. The serum concentration of total proteins, albumin, urea, glucose, NEFA,
Table 1. Chemical composition of diets used during steaming-up and subsequent early lactation.

\begin{tabular}{lrr}
\hline Chemical composition $(\%)$ & Steaming-up & Early lactation \\
\hline Crude protein & 12.87 & 16.66 \\
Ethereal extract & 4.55 & 5.32 \\
Ash & 7.83 & 7.34 \\
NDF & 43.99 & 33.41 \\
NFC & 33.56 & 38.27 \\
Dry matter degradable & 59.68 & 68.22 \\
ADF & 24.46 & 20.12 \\
Starch & 16.49 & 25.94 \\
\hline
\end{tabular}

NDF (neutral detergent fiber), ADF (acid detergent fiber), NFC (non-fiber carbohydrates).

and BHB were assessed with commercial kits using an automated spectrophotometer according to the manufacturer's instructions (Slim, Seac Banche SpA, 50144 Florence, Italy). The globulin values were calculated by subtracting the values of albumin from the corresponding values of total proteins. The $A / G$ (albumin concentration/globulin concentration) ratio was calculated. Depending on calf gender, cows were grouped into two groups: Group 1 consisted of cows (3.6 mean lactation number) calving heifers, $n=12$, and Group 2 consisted of cows (3.7 mean lactation number) calving bulls, $n=8$. In Group 1, T1 was $4.6 \pm 1.8$ days, and in Group 2, T1 was $4.4 \pm 0.9$ days before partum.

A two-way repeated measures analysis of variance (twoway ANOVA) was used to evaluate the influence of time and offspring sex effects on the metabolic parameters of blood samples. Unpaired data were analysed using the Student's $t$ test for independent samples. $P$ values $<0.05$ were considered statistically significant. All data were analysed using Statistica 8 software (Statsoft Inc., Tulsa, OK, USA).

\section{Results}

The results of the statistical analysis on the nitrogen parameter data in the early transition period are illustrated in Fig. 1. For Group 1, total proteins were significantly higher during T3 than during T1 $(P<0.05)$, whereas total protein levels in Group 2 were not significantly altered. Total protein levels in Group 2 compared with those in Group 1 were significantly lower at T3 $(P<0.05)$. Albumin levels in Group 2 were significantly higher than those in Group 1 at T1 $(P<0.01)$, whereas at T3 they were significantly higher in Group 1 than in Group $2(P<0.05)$. A similar effect at T3 was found for total globulins with significantly higher levels in Group 1 than in Group $2(P<0.05)$. The $A / G$ ratio significantly decreased in both groups of cows at T2 $(P<0.05)$ and at T3 $(P<0.05)$ when compared to T1. Urea levels in both groups of cows also significantly decreased at $\mathrm{T} 2$ when compared to $\mathrm{T} 1(P<0.05)$. At T2, levels of urea were significantly lower in Group 2 than in Group $1(P<0.05)$. 

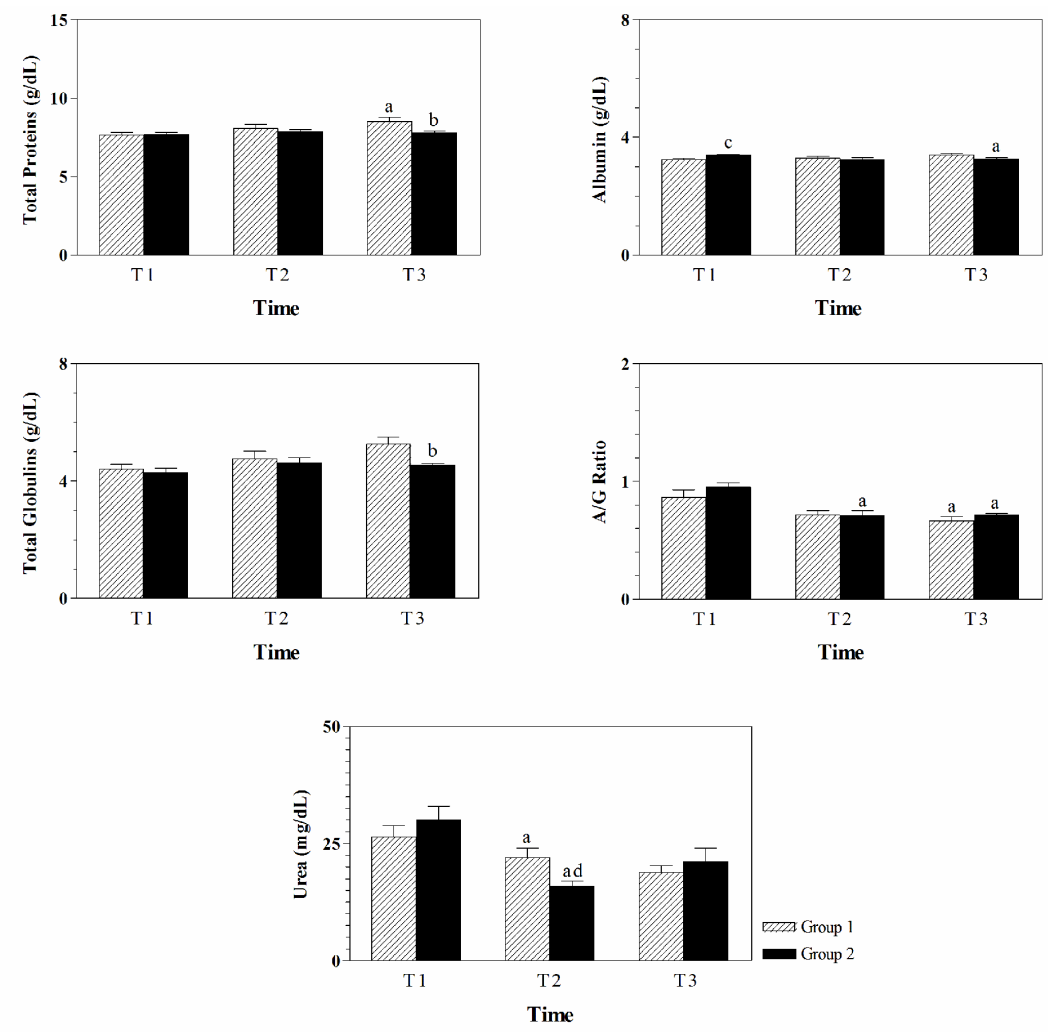

Significance (Time): $\quad{ }^{a}$ vs.T1 $(P<0.05)$
Significance (Group): $\quad{ }^{b}$ vs. Group 1 at T3 $(P<0.05) ; \quad$ vv. Group 1 at T1 $(P<0.01) ; \quad \mathrm{d}_{\mathrm{vs} . \text { Group } 1 \text { at T2 }(P<0.05)}$

Figure 1. Pattern of total proteins, albumin, globulins, $A / G$ ratio, and urea in Group 1 and Group 2 dairy cows monitored at 1 week before the expected partum (T1), and at 1 week (T2) and 2 weeks (T3) after.

Figure 2 shows the results of the analysis on energy parameters. A significant effect of time was found on the NEFA pattern for both groups of cows. For Group 1, levels were significantly increased at $\mathrm{T} 2$ and $\mathrm{T} 3$ when compared to $\mathrm{T} 1$ $(P<0.05)$. The levels in Group 2 were significantly higher at T2 $(P<0.05)$ but lower at T3. When compared with Group 2, Group 1 had significantly higher NEFA levels at T3 $(P<0.05)$ and significantly higher glucose levels at T2 $(P<0.01)$ and $\mathrm{T} 3(P<0.05)$.

\section{Discussion}

The results of this study indicate that the sex of the offspring can affect nitrogen and energy metabolism during the transition period in Holstein Friesian dairy cows. The increase in total proteins, albumin, and globulins in dams of heifers could suggest a greater dehydration than what was observed for dams of bulls. These differences could be a result of offspring gender differences in physiological dehydration which is generally linked with increased milk production. Serum protein patterns can provide information about dehydration in dairy cows during the peripartum period (Piccione et al., 2011). Although Hinde et al. (2014) reported that gestation of a daughter on the first parity increased milk production over the first two lactations, we have no data for cows in their third to fifth lactation in this study. Since dams of heifers showed a greater plasma dehydration than dams of bulls, it is possible that they also have greater milk production; however, further studies are necessary to validate this hypothesis. While there were increases in serum protein parameters, these concentrations remained within the normal range reported for dairy cows (Alberghina et al., 2011). The different percentage changes in albumin and globulins also suggest that mechanisms other than dehydration may be involved in these differences. Low albumin levels associated with low urea levels are due to reduced protein catabolism - quite normal in this condition of protein anabolism.

Cows calving bulls had significantly higher levels of albumin at $\mathrm{T} 1$ and significantly lower levels of total proteins at T3. These results could be due to a different long-term effect of sex hormones on liver metabolism. It is possible that the significant decrease in $A / G$ observed after gestation indicates a shift towards milk synthesis. It is also possible that 

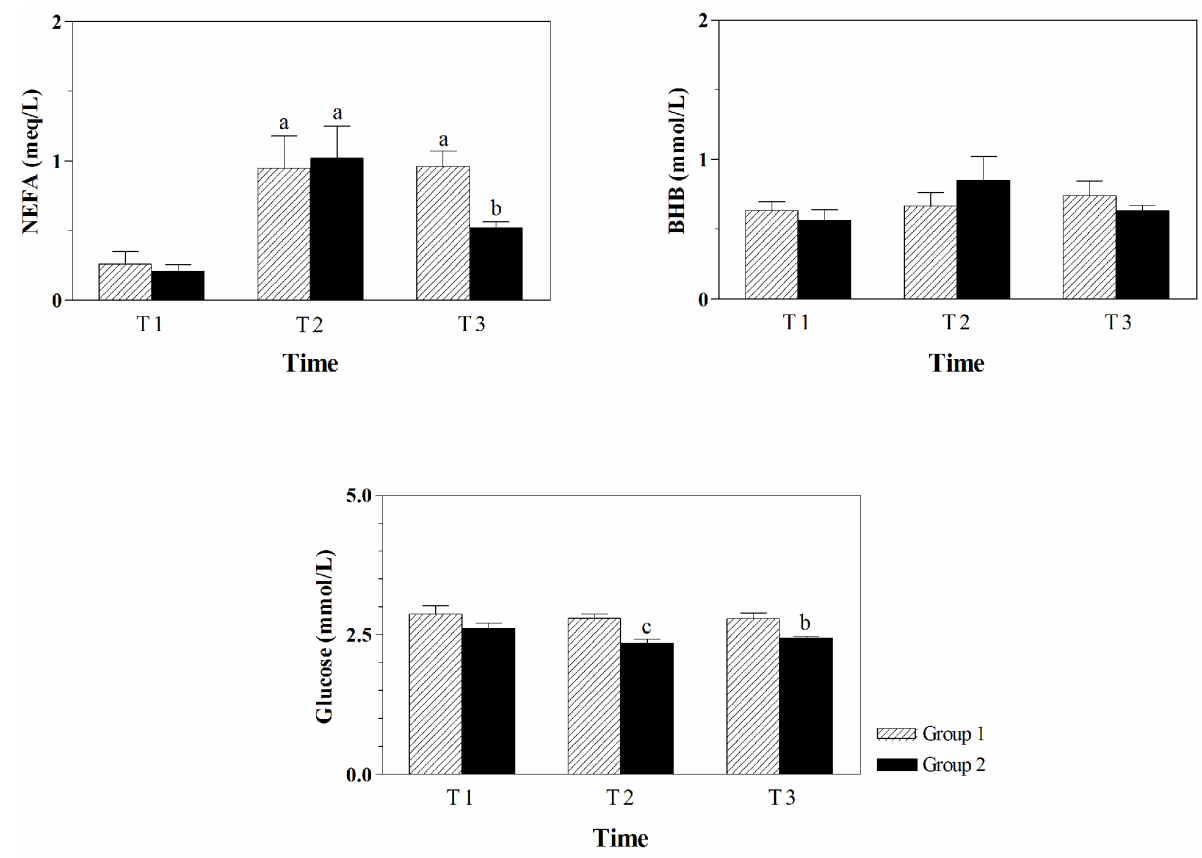

Significance (Time): $\quad{ }^{\mathrm{a}} \mathrm{vs.} \mathrm{T} 1(P<0.05)$
Significance (Group): $\quad{ }^{\mathrm{b}}$ vs. Group 1 at T3 $(P<0.05) ; \quad{ }^{\mathrm{c}} \mathrm{vs}$. Group 1 at T2 $(P<0.01)$

Figure 2. Pattern of glucose, BHB, and NEFA in Group 1 and Group 2 dairy cows monitored at 1 week before the expected partum (T1), and at 1 week (T2) and 2 weeks (T3) after.

during the last stage of pregnancy, immunoglobulins leave the plasma when colostrum is formed in the mammary gland, which results in high prepartum values of $A / G$.

The decrease of urea postpartum could be due to a decrease in nitrogen catabolism for milk protein synthesis. Values found at $\mathrm{T} 2$ in Group 2 cows are significantly lower than values in Group 1. Furthermore, this pattern difference could be explained by a long-term effect of fetal sex hormones on nitrogen metabolism. It is possible that male hormones divert proteins from catabolism to tissue formation in dams rather than in protein milk since lower milk yield for bulls is not compensated by higher protein and fat production (Hinde et al., 2014).

Serum glucose in dairy cows is derived mostly from gluconeogenesis. The findings that there were lower glucose concentrations in Group 2 cows pre- and postpartum than Group 1 cows suggest that gluconeogenesis in cows calving bulls is less effective in increasing blood glucose than those calving heifers. One regulator of glucose in ruminants is cortisol, which acts to increase gluconeogenesis from amino acids (Trenkle, 1981). It is possible that fetal sex could also affect cortisol levels during pregnancy as differences in cortisol have been reported in humans. For instance,women carrying male fetuses had lower levels of salivary cortisol during the second half of pregnancy compared with those carrying female fetuses (Di Pietro et al., 2011). For dairy cows, however, it is unknown as to whether there are differences in maternal cortisol levels related to differences in fetus gender. On the other hand, INSL3, a fetal hormone that is present only in cows carrying bull calves, has been reported to affect placental and maternal physiology (Anand-Ivell et al., 2011). It is possible that this hormone also affects postpartum glucose levels in cows with bull calves. In dairying, calves are removed on the day of birth and standardized mechanical procedures are used for milking, therefore results of sex differences on postpartum maternal serum are difficult to explain. Further studies are necessary to clarify these results.

Increased NEFA postpartum increases lipolysis of adipose tissue reserve in response to the energy deficit (Roche et al., 2009). In this study, the significantly higher levels of NEFA in Group 1 cows at T2 indicates a greater mobilization of energetically important tissue than in Group 2 cows, which could also explain the findings that total production of milk energy was greater in cows with a heifer calf (Hinde et al., 2014).

Taken together, the results of this study show that there are differences in hepatic metabolism in cows after partus of a bull or heifer. While BHB was not significantly affected by time or gender, there were significantly lower postpartum levels of total protein, albumin, urea, and glucose in cows 
with a bull than those with a heifer calf. Dairy cows undergo many metabolic adaptations as they transition from late pregnancy to early lactation. While these changes are normally coordinated by maternal hormones, the present findings suggest that fetal hormones also play a significant role in altering the physiological state of the cow during the transition period.

Acknowledgements. This work has been supported by the research funds of PRA 2013 code 60A08-0083/13 of the University of Padua. We would like to thank Francesca Arfuso for her valuable help in manuscript preparation and Winnie Y. Chan for her comments and help in English correction.

Edited by: A.-E. Freifrau von Tiele-Winckler

Reviewed by: two anonymous referees

\section{References}

Adamski, M., Kupczyński, R., Chladek, G., and Falta, D.: Influence of propylene glycol and glycerin in Simmental cows in periparturient period on milk yield and metabolic changes, Arch. Tierz., 54, 238-248, 2011.

Alberghina, D., Giannetto, C., Vazzana, I., Ferrantelli, V., and Piccione, G.: Reference Intervals for Total Protein Concentration, Serum Protein Fractions, and Albumin/Globulin Ratios in Clinically Healthy Dairy Cows, J. Vet. Diagn. Invest., 23, 111-114, 2011.

Anand-Ivell, R., Hiendleder, S., Viñoles, C., Martin, G. B., Fitzsimmons, C., Eurich, A., Hafen, B., and Ivell, R.: INSL3 in the Ruminant: A Powerful Indicator of Gender- and Genetic-Specific Feto-Maternal Dialogue, PLoS One, 6, e19821, doi:10.1071/RD11281, 2011.

Córdova-Izquierdo, A., Xolalpa Campos, V. M., Gustavo Ruiz Lang, C., Saltijeral Oaxaca, J. A., Cortés Suárez, S., CórdovaJiménez, C. A., Córdova-Jiménez, M. S., Peña Betancurt, S. D., and Guerra Liera, J. E.: Effects of the Offspring's Sex on Open Days in Dairy Cattle, J. Anim. Vet. Adv., 7, 1329-1331, 2008.

De Vries, A.: Economics of Delayed Replacement When Cow Performance is Seasonal, J. Dairy Sci., 87, 2947-2958, 2004.

DiPietro, J. A., Costigan, K. A., Kivlighlan, K. T., Chen, P., and Laudenslager, M. L.: Maternal salivary cortisol differs by fetal sex during the second half of pregnancy, Psychoneuroendocrinology, 36, 588-591, 2011.

Grant, V. J. and Chamley, L. W.: Can mammalian mothers influence the sex of their offspring peri-conceptually?, Reproduction, 140, 425-433, 2010.
Grant, V. J., Irwin, R. J., Standley, N. T., Shelling, A. N., and Chamley, L. W.: Sex of Bovine Embryos May Be Related to Mothers' Preovulatory Follicular Testosterone, Biol. Reprod., 78, 812815, 2008.

Hardy, I. C. W.: Possible factors influencing vertebrate sex ratios: an introductory overview, Appl. Anim. Behav. Sci., 51, 217-241, 1997.

Hinde, K., Carpenter, A. J., Clay, J. S., Bradford, B. J.: Holsteins Favor Heifers, Not Bulls: Biased Milk Production Programmed during Pregnancy as a Function of Fetal Sex, PLoS One, 9, e86169, doi:10.1371/journal.pone.0086169, 2014.

Klisch, K. and Mess, A.: Evolutionary Differentiation of Cetartiodactyl Placentae in the Light of the Viviparity-Driven Conflict Hypothesis, Placenta, 28, 353-360, 2007.

Kupczyński, R., Adamski, M., Falta, D., Chládek, G., and Kruszyński, W.: The influence of condition on metabolic profile of Czech Fleckvieh cows in the perinatal period, Arch. Tierz., 54, 456-467, 2011.

McArt, J. A. A., Nydam, D. V., and Oetzel, G. R.: Dry period and parturient predictors of early lactation hyperketonemia in dairy cattle, J. Dairy Sci., 96, 198-209, 2013a.

McArt, J. A. A., Nydam, D. V., Oetzel, G. R., Overton, T. R., and Ospina, P. A.: Elevated non-esterified fatty acids and $\beta$ hydroxybutyrate and their association with transition dairy cow performance, Vet. J., 198, 560-570, 2013b.

Müller, U., Sharif, A. R., Staufenbiel, R., Hasselmann, L., Tripmacher, R., Wiebe, J., and Brockmann, G. A.: Rearing diet effects on body condition and milk performance in first lactating dairy cows - A longitudinal study, Arch. Tierz., 48, 417-427, 2005.

Oetzel, G. R.: Monitoring and testing dairy herds for metabolic disease, Vet. Clin. Food Anim., 20, 651-674, 2004.

Piccione, G., Messina, V., Schembari, A., Casella, S., Giannetto, C., and Alberghina, D.: Pattern of serum protein fractions in dairy cows during different stages of gestation and lactation, J. Dairy Res., 78, 421-425, 2011.

Piccione, G., Messina, V., Marafioti, S., Casella, S., Giannetto, C., and Fazio, F.: Changes of some haematochemical parameters in dairy cows during late gestation, post partum, lactation and dry periods, Vet. Med. Zoot., 58, 59-64, 2012.

Roche, J. R., Friggens, N. C., Kay, J. K., Fisher, M. W., Stafford, K. J., and Berry, D. P.: Invited review: Body condition score and its association with dairy cow productivity, health, and welfare, J. Dairy Sci., 92, 5769-5801, 2009.

Tóthová, C., Nagy, O., and Kováč, G.: Relationship between some variables of protein profile and indicators of lipomobilization in dairy cows after calving, Arch. Tierz., 57, 1-9, 2014.

Trenkle, A.: Endocrine regulation of energy metabolism in ruminants, Fed. Proc., 40, 2536-2541, 1981.

West, H. J.: Effect on liver function of acetonaemia and the fat cow syndrome in cattle, Res. Vet. Sci., 48, 221-222, 1990. 